DEBATE 


\title{
Cuestiones de metodología cualitativa ${ }^{1}$
}

\author{
Miguel Ángel Castro Nogueira \\ Departamento de Sociología \\ UPCO \\ LUIS CASTRO NogUeIRA \\ Departamento de Sociología I \\ Teoría, Metodología y Cambio Social \\ UNED
}

\section{EL PROBLEMA DEL MÉTODO EN LA INVESTIGACIÓN CUALITATIVA}

La aspiración metodológica tradicional ha estado orientada al descubrimiento de procedimientos y estrategias de investigación que garanticen resultados verdaderos. Por método se ha entendido, tradicionalmente, un conjunto ordenado de acciones u operaciones realizado conforme a ciertas reglas que constituye un procedimiento adecuado para alcanzar un fin del conocimiento. Los principales rasgos de todo método, según esta conceptualización, serían:

Ser un conjunto normativo de acciones: es característico del método su oposición al azar, pues el método es siempre un orden articulado por un conjunto de reglas; en este sentido, el método se nos representa como un camino

\footnotetext{
${ }^{1}$ Estas páginas han surgido como respuesta a una necesidad de clarificación epistemológica, teórica y metodológica. Los autores de este artículo trabajan desde el segundo semestre de 1999 en una investigación empírica cuyo objeto de análisis es la Unidad de Cuidados Intensivos de un gran hospital del Servicio Público de Salud en Madrid. Esta UCI, como cualquier otra, es un espacio privilegiado en el que convergen aspectos funcionales, físicos y simbólicos que hacen de ella un objeto de altísima densidad simbólica. Dicha investigación se aborda, en su fase de campo, desde una perspectiva cualitativa, cuyo diseño ha obligado a los autores a afrontar una revisión de los fundamentos de esta metodología. Estas páginas representan una parte de ese esfuerzo de (auto)clarificación. Concretamente, este artículo afronta un conjunto de temas centrales para la metodología cualitativa tales como la falta de unidad teórica y metodológica, los rasgos específicos de los objetos de investigación característicamente cualitativos y el problema de la representatividad de las conclusiones. En cierto modo, estas páginas presuponen las opiniones vertidas por los autores en su ensayo Hacia una correcta comprensión de la metodología cualitativa (Castro y Castro, 2001, Rev. Política y Sociedad, en prensa) en el que se afrontaba una clarificación conceptual de esta perspectiva desde los planos ontológico-epistemológico y teórico.
} 
seguro para obtener nuestro propósito, como una mediación estable entre conocimiento y realidad.

La independencia objetiva del sujeto investigador: la noción de método incluye también la idea de independencia objetiva del sujeto que lo pone en práctica; es decir, es característico del método, de cualquier método, ofrecer un procedimiento objetivo que, de ser aplicado correctamente, debe ofrecer resultados estimables sea quien sea quien lo ejecute.

Claridad y precisión de los conceptos y reglas aplicadas: todo método debe articularse de modo que su sentido no esté sujeto a interpretación, pues la claridad de sus reglas y de sus criterios de aplicación son la garantía operativa de su adecuada implementación.

Reconocimiento de la comunidad científica: los métodos, particularmente aquellos que etiquetamos como métodos científicos, suelen gozar de reconocimiento público en el seno de la comunidad científica, la cual los avala como garantía de validez.

Sin embargo, la noción actual de método ha rebajado notablemente sus aspiraciones frente al delirio cartesiano que lo concebía como una suerte de mediador mágico entre conocimiento y verdad. La noción unitaria de método ha sido sustituida por la aceptación de una pluralidad metódica irreductible que debe comprenderse en subordinación a consideraciones ontológico-epistemológicas, metacientíficas y a paradigmas teóricos (Castro y Castro, 2001, en prensa). Actualmente, la noción de método se aproxima más a la de protocolo de investigación, es decir, la explícita y pública enunciación del conjunto de conceptos, hipótesis, instrumentos y mediciones que constituyen la norma de trabajo en el seno de una investigación y de una comunidad científicas. Es decir, lo que valoramos hoy con especial énfasis es la exposición detallada del procedimiento a seguir y de su fundamentación, por encima de su adecuación a una forma estandarizada. Esta afirmación, así lo creemos, puede mantenerse con solvencia en el ámbito de las ciencias sociales -y en buena medida en cierta investigación de las ciencias de la naturaleza-.

No obstante, aún en este marco profundamente revisado, la investigación cualitativa 2 (IC.), hoy por hoy, no posee un sistema metodológico y técnico suficientemente cerrado y consensuado que pueda presentarse como estándar de control de calidad metodológica y que unifique, en lo posible, la praxis investigadora. No debe interpretarse esta afirmación como un síntoma de anhelo unificacionista o un lamento. Antes bien, como argumentaremos, esta situación es el resultado de un conjunto de factores algunos de los cuales constituyen límites estructurales a la institucionalización metodológica de este tipo de investigación, a la vez que expresan su especificidad. Estos factores organizan en torno a tres focos: $a$ ) a la falta de consenso teórico y metodológico dentro de la comunidad científica, $b$ ) a la brecha existente entre teoría -psicológica, sociológica y semió-

2 Para una clarificación del concepto investigación cualitativa en la línea argumental que se utiliza en este artículo ver Castro, M. y Castro, L. 2001, cír. supra nota 1; para ampliar esta perspectiva, aunque con diferencias significativas, ver Ibañez, 1979, 1985; Ortí, 1986, 1994; Alonso, 1998; Delgado y Gutiérrez, 1994. 
tica- y la práctica investigadora y $c$ ) a ciertos rasgos particulares que caracterizan a toda investigación cualitativa, a saber, flexibilidad y contextualidad, carácter abierto del diseño, orientación holista y naturaleza interpretativa del análisis. A continuación analizaremos estas limitaciones.

La falta de unidad teórica y metodológica ${ }^{3}$ es un serio handicap que hemos intentado analizar en otro lugar (Ibidem ). Este disenso se manifiesta tanto en cuestiones nominales y de nomenclatura, -como en la misma denominación genérica: investigación cualitativa, métodos cualitativos, técnicas cualitativas de investigación social, mirada cualitativa...-, como en cuestiones sustantivas de alcance ontológico-epistemológico y teórico -como la coexistencia de varios paradigmas teóricos alternativos: psicologista, sociologista y semiótico (Ibidem)-. Si adoptamos como expresión más genérica y menos comprometida la de investigación cualitativa, podemos afirmar que, en torno a ella, el mayor grado de consenso se produce, al menos aparentemente, en la identificación y adscripción de un conjunto de técnicas "característicamente cualitativas», como la entrevista en profundidad o el grupo de discusión. Sin embargo, el aparente consenso alcanzado en el listado de técnicas encierra diferencias importantes en el plano teórico-metodológico y también en algunas especificaciones puramente operativas. Estas diferencias están en íntima relación con la oposición entre los distintos paradigmas teóricos, mencionados anteriormente, pues cada uno de ellos concibe y ordena de modo diferente la práctica investigadora. Por todo ello, creemos justificado hablar de una doble significación de la expresión investigación cualitativa. Así, podemos distinguir entre una concepción o significación ampliada y una concepción o significación restringida de la I.C. En su sentido ampliado, la $I C$. se presenta como una verdadera episteme alternativa, como un gran paradigma orientado a ordenar, desde el nivel de mayor compromiso ontológico, epistemológico y teórico la reflexión de las ciencias sociales y de la investigación social. Encerrando en sí misma diferentes orientaciones teóricas y metodológicas (cfr. nota 3), no siempre convergentes, la IC. se asimila así a otras demarcaciones más tradicionales y reivindica para sí, cuando menos, una irre-

${ }^{3}$ La diversidad de orientaciones teóricas y metodológícas en la IC es muy notable. Simplificando enormemente podemos hablar de dos tradiciones profundamente distantes: de una parte, la tradición angloamericana, con raíces en el interaccionismo simbólico y el pragmatismo norteamericano, pero que se ramifica enormemente bebiendo del constructivismo, la etnometodología, la emografia, etc, (con nombres como Glaser, Strauss, Corbin, Guba, Lincoln, Patton, ...) y de otra parte, ligada al debate entre hermenéutica y estructuralismo, una tradición nétamente española, aunque con ecos y raíces en el continente, desarrollada por Jesús Ibañez y la denominada «escuela cualitativista de Madrid». Cualquiera que se asome a esta pluralidad de enfoques se hará cargo enseguida de lo que queremos decir con «falta de unidad teórica y metodológica». En este ensayo, sin embargo, nuestros referentes son dos: en primer lugar, la orientación estructural, netamente española, en cuya órbita nos situamos; de otra, la práctica de la investigación cualitativa en la investigación de mercados tal y cómo se desarrolla en nuestro contexto. Así, este ensayo debe entenderse como un diálogo con ambas realidades a las que los autores interpelan y por las que se sienten interpelados. Para una exposición más profunda de nuestro parecer sobre esta pluralidad y sus origenes cfr. Castro, M. y Castro, L. 2001, supra nota 1 y Castro, M. La Imagen de la ICen la investigación de mercados, ponencia presentada en el VII Congreso Español de Sociología, Salamanca, 2001. 
ductible identidad epistemológica y, en ocasiones, una superioridad epistemológica y axiológica. En este sentido, la $I C$. se presenta, según autores y tradiciones, asociada/identificada con: la sociología crítica y dialéctica, la sociología comprensiva, la hermenéutica, el psicoanálisis, la semiótica, la fenomenología, el interaccionismo simbólico y el pragmatismo, la etnografía... Mientras tanto, en su sentido restringido, la $I C$. se presenta como un tipo de investigación social definida a partir del uso de un conjunto de técnicas específicas: la entrevista en profundidad o entrevista abierta semidirectiva -deep interview-, el grupo de discusión o dinámica de grupo -focussed group-, la observación, cierto tipo de análisis (cualitativo) de contenido o las investigaciones de documentos personales y biográficas. En esta acepción, el perfil epistemológico y teórico es más bajo, adquiriendo un mayor protagonismo las cuestiones metodológicas y técnicas, y con ello todo lo relativo al diseño de la investigación y a las estrategias operativas para el trabajo de campo, el registro de la información y las consignas para el análisis de la información. En este sentido, la IC. se opone con mayor evidencia a la investigación cuantitativa que utiliza instrumentos muy estructurados para obtener información y procedimientos matemático-estadísticos para su análisis. Esta polarización, que puede rastrearse fácilmente en la bibliografía al uso, nos da pie a plantear la segunda razón por la que la $I C$. cuenta con poco consenso teórico y metodológico: la brecha entre teoría y práctica investigadora.

En un contexto tan poco académico y tan pragmático como es el de la investigación de mercados. Reuter (1995) y Valentine (1995) han señalado con acierto esta circunstancia de capital importancia: el abismo que separa las complejas construcciones teóricas y los criterios operativos de investigación. Aunque las aportaciones de ambos autores no son plenamente coincidentes, sí comparten la preocupación por un conjunto de hechos, algunos coyunturales, otros estructurales, que configuran un vacío metodológico difícil de llenar.

En síntesis, y adaptados por nosotros, esos hechos son los siguientes: 1) la investigación cualitativa pone en juego un complejo sistema de conceptos y teorías con las que construye su objeto de investigación y afronta la tarea de interpretarlo. Esos conceptos y teorías se sitúan en un nivel de abstracción muy rico, pero muy elevado (motivaciones inconscientes, discurso social, imaginario social, representación social...), de suerte que, cuando queremos traducirlos en fenómenos observables e identificables que puedan ser registrados, encontramos enormes dificultades en su operacionalización. Por así decir, la $I C$. adolece de una cierta inflación teórica y un notable subdesarrollo metodológico; 2) aunque pueda decirse lo mismo de otras orientaciones (nada hay más abstruso que la refinada estadística), la IC. pone en juego modelos teóricos -y disciplinas- desarticulados y con cierta aura de esoterismo. Sin que ello suponga, en modo alguno, una intención deslegitimadora, hemos de asentir al afirmar que la $I C$. se sirve de un buen número de saberes «científicamente proscritos», bordeando, casi siempre, las fronteras de la demarcación científica más ortodoxa. Aunque esta no sea por sí misma una razón suficiente para que la IC. deba abdicar de sus pretensiones gnoseológicas, sin embargo hemos de admitir que es una circunstancia que dificulta la institucionalización de los métodos y de sus marcos teóricos; 3) la investigación cualitativa tiende a representarse como un proceso no sistematiza- 
ble, marcadamente «artístico», en el que el genio (Kant, I, 1790), la intuición y la creatívidad del investigador juegan un papel del todo irreductible; los que así conciben la $I C$., se resisten a protocolarizar los diseños de investigación, por ser éste un propósito superfluo y, últimamente, inviable. Esta perspectiva está muy extendida tanto en la producción más sesuda y académica, como en la pragmática investigación de mercados ${ }^{4}$. Cuando este punto de vista, sin duda fundado en alguna medida, se adopta como principio básico en la concepción de la $I C$. todo intento sistematizador, metodológico y técnico, pasa a un segundo plano y es tenido, incluso, como un sometimiento bastardo a los intereses y normas epistemológicas impuestas por el imperialismo positivista. No resulta sencillo dirimir esta cuestión, pues la $I C$, en tanto que praxis, no permite su protocolarización; ahora bien, como orientación nos parece fundamental apostar por un trabajo de sistematización metodológica y técnica que asuma las limitaciones inherentes a este tipo de investigación y, sobre todo, eliminar toda «mística» intuicionista del discurso teórico y metodológico 5. 4) Otra dificultad inherente al proceso de $I C$. estriba en su naturaleza hermenéutica; se ha defendido con acierto que este tipo de investigación es, en último término, una hermenéutica, es decir, una interpretación de los componentes expresivos de la actividad humana y de sus formas de organización, particularmente, de la conducta lingüística (habla/actuación) y de sus correlatos discursivos (lengua/competencia). Ese proceso hermenéutico intenta comprender y descubrir la lógica de la formación de los significados ideológicos, representaciones e imágenes que configuran los universos simbólicos, los sistemas de representación y los imaginarios sociales, así como sus formas de legitimación y deslegitimación, de conservación y cambio y de interacción con la biografía particular de los agentes. Para ello, las manifestaciones expresivas deben ponerse en relación con múltiples circunstancias estructurales, situacionales, semióticas, psicosociales y pragmáticas. Toda actividad hermenéutica aboca al proceso de investigación a un recorrido circular en el que se camina, constantemente, del todo a la parte, del pasado al futuro y de este de nuevo al pasado, ... de modo que el sentido surge como resultado de un trabajo que en modo alguno es reductible a un proceso lineal 6 . A nuestro juicio, la $I C$. debe hacer compatible el reconocimiento de su naturaleza hermenéutica con un empeño denodado por hacer manifiesto, público y consciente, a priori en lo que sea posible y a posteriori en el resto, el proceso de investigación tal y como se ha desarrollado. En este sentido, puede afirmarse que toda investigación cualitativa tiene en el formato narrativo un modelo consustancial a su naturaleza. 5) Por último, Reuter y Valentine alertan sobre una circunstancia que, aunque difícil de manejar, no pue-

\footnotetext{
4 Algo de esto subyace en la postura de Ibañez, Ortí y Alonso, al tiempo que, en el ámbito de la investigación cualitativa en marketing, publicidad y opinión pública, es la opinión más extendida.

5 Son muy importantes los esfuerzos realizados en esta dirección por algunos autores en nuestro contexto; véase, por ejemplo, Gutiérrez y Delgado, 1994 o, en otra dirección, Vallés, 1997.

${ }^{6}$ Esta peculiaridad a la que nos referimos, por otra parte, no es más que la traslación al ámbito de las ciencias sociales del famoso círculo hermenéutico que tematizaron Heidegger, Gadamer o Ricoeur, y que nos remite a los orígenes de la hermenéutica filosófica con Schleiermacher y Dilthey.
} 
de obviarse. Para ellos es un hecho que, en el campo de la investigación de 7 mercados, la $I C$. posee una imagen de saber esotérico y hermético . La IC. es, así, una suerte de «caja negra» cuyo contenido y lógica interna permanecen ocultos por completo para la mayor parte de sus beneficiarios. Sólo aquellos que poseen este saber, los iniciados, comprenden su naturaleza y, de este modo, clientes, empresas, instituciones... permanecen en la ignorancia acerca de lo que es el proceso de investigación. ¿Cómo se ha llegado a los resultados?, ¿por qué se ha seguido este proceso?... Para los autores, esta circunstancia es el resultado de la complicidad de investigadores -beneficiados por su aura de sabios irremplazables-y de clientes - preocupados, tan sólo, por los resultados, particularmente si les son propicios-. No cabe duda de que estas reflexiones suponen un juicio de intenciones que no es fácil demostrar, y que, además, aparece contextualizado en el campo de la investigación comercial. Sin embargo, lo que subyace a esa crítica si puede ser rescatado: el saber es poder, el lenguaje técnico es una forma de dominación y la oscuridad una defensa.

Una última dificultad se encuentra en algunos rasgos consustanciales al diseño de la IC. Frente a la orientación normativa de la noción de método la investigación cualitativa elabora diseños abiertos y flexibles. Por tal se entiende la incorporación sistemática y planificada de resultados parciales al propio diseño de investigación; esto significa que cada etapa de la investigación condiciona en tiempo real el desarrollo de las siguientes fases, por lo que la planificación de medios, los criterios muestrales, la selección de técnicas, incluso elementos sustantivos como las hipótesis del proyecto, pueden verse alterados conforme avanza la investigación. Por otra parte, la IC. es tanto más potente cuanto más concreto, limitado y «denso» sea el objeto de estudio, es decir, cuanto más focalizada se encuentre. Esta orientación intensiva y focalizadora hace que cada proyecto metodológico se encuentre fuertemente contextualizado y sea muy dependiente de las condiciones concretas y particulares en las que se desarrolla. Por orientación holista se entiende la disposición epistemológica y metodológica de la IC. a contemplar y analizar los fenómenos como totalidades estructurales antes que como agregados de partes independientes. Este rasgo viene a manifestar en un plano de mayor abstracción lo que antes hemos expuesto en términos operativos: en la medida en que cada fenómeno encuentra su sentido más completo considerado en el seno de la estructura a la que pertenece, el proceso de interpretación no concluye hasta que no se le haya puesto en relación con cada aspecto pertinente de la totalidad -totalidad que sólo quedará iluminada después de que se hayan estudiado, a su vez, cada una de sus partes-. Por último, aún a riesgo de repetirnos, debemos subrayar el carácter interpretativo de la $I C$. Se ha dicho ya que se trata de un tipo de investigación eminentemente hermenéutica y que su orientación holista define este trabajo de interpretación de modo esencial. Pero no debe

${ }^{7}$ Los autores citados circunscriben su afirmación al campo de la investigación de mercados y la fundan en su experiencia profesional. Para reforzar esta afirmación en el contexto comercial español, Castro, M. La imagen de la IC en la investigación de mercados, op. Cit. Nota 3. Más allá del contexto comercial se concederá que algo de esto puede percibirse en la imprescindible obra de Jesús Ibanez. 
dejar de advertirse algo que creemos fundamental y muy singular de este tipo de investigación: la IC. intenta asumir y hacer manifiesta esta «circularidad» que, por otra parte no le pertenece de modo exclusivo. La epistemología actual viene a subrayar esta circularidad entre empiria y teoría, entre la parte y el todo, entre la observación y el instrumento, como una condición consustancial a toda forma de conocimiento. Pero mientras que la investigación de corte objetivista y cientista tiende a obviar este problema y a trabajar como si el proceso de investigación fuese lineal, secuencial y continuo, la $I C$. aborda el problema intentando incorporar manifiestamente esta condición epistemológica al diseño metodológico y técnico, asumiendo al sujeto investigador como sujeto en proceso y a la investigación como fenómeno reflexivo.

\section{EL OBJETO DE ESTUDIO. LA PERTINENCIA DE LA METODOLOGÍA CUALITATIVA}

La eficacia y adecuación de la metodología cualitativa depende de tres circunstancias iniciales que caracterizan al tipo de objeto que es susceptible de ser abordado desde esta perspectiva. Así:

a) a mayor concreción del objeto de estudio, mayor eficacia analítica de la metodología cualitativa: los diseños cualitativos que se enfrentan a campos de investigación muy abiertos pierden potencia analítica e interpretativa, so pena de requerir una planificación y un desarrollo desproporcionado y alejado, por lo común, de las posibilidades materiales de la investigación social más frecuente.

b) a mayor densidad simbólica y significativa del objeto de estudio, mayor potencia analítica: cualquier fenómeno social es susceptible de ser abordado cualitativamente; sin embargo, aquellos fenómenos que por su naturaleza acumulan una mayor carga de significados, contenidos psicosociales y culturales en una limitada porción de realidad acotable, serán el objeto preferencial de esta metodología.

c) a mayor precisión de los objetivos y, por tanto, a menor extensión de las conclusiones, mayor validez de los resultados.

Ortí $(1986,1994)$ ha señalado con lucidez las exigencias noemáticas que caracterizan a la investigación cualitativa. El objeto cualitativo por antonomasia es aquel que se encuentra sobredetermínado y supersaturado simbólica, ideológica e imaginariamente. Muchos productos y servicios en la esfera del consumo cumplen ejemplarmente estos rasgos, por lo que la $I C$. resulta muy adecuada en ese contexto. Así ocurre, por ejemplo, al analizar una breve comunicación publicitaria -vg. la comunicación corporativa de alguna gran empresa- en la que, en apenas veinte segundos, podemos encontrar un componente referencial expreso -nombre y logo de la empresa, sector de producción, producto bandera,...acompañado de recursos expresivos y retóricos que proyectan una imagen diseñada para suscitar la identificación y el interés del target: por ejemplo, subra- 
yando el componente técnico-científico de la compañía y su actividad; su respeto por la naturaleza y el medio ambiente; su compromiso social con los más necesitados; su origen arquetípico -USA solutions-, su penetración en el mercado mundial, etc... Y todo ello sumamente comprimido espacio-temporalmente y referido a un objeto concreto. Otro ejemplo de máxima densidad y concreción lo tenemos en las pruebas para el diseño de nuevos productos, tanto en su fase de concepto como en las condiciones concretas del diseño del envase y el embalaje. En apenas unos centímetros, la presentación de un producto contiene un sinfín de determinaciones proyectadas explícita e implícitamente a partir de innumerables elementos comunicativos: categoría del producto, marca, precio, orientación específica hacia un género, una edad, una clase social, un estilo de vida, las condiciones estéticas del diseño, aspectos funcionales, etc... Así, cada palabra, cada expresión y giro, cada código y cada imagen, el color, la forma, el tamaño, el diseño, el precio, el punto de venta, su posicionamiento diferencial, la disposición en el lineal, la imagen de marca asociada, etc,... .todo, absolutamente todo, comunica para convertir al producto en un ente $n$-dimensional cuidadosamente posicionado en el mercado e intencionalmente orientado hacia su público objetivo.

Más allá del ámbito de la investigación de mercados y publicitaria, la $I C$. puede mantener sus pretensiones gnoseológicas siempre que afronte objetos de investigación que reproduzcan esta sobredeterminación y superconcreción. Puede servir de ejemplo de esta clase de objetos la organización de una Unidad de Cuidados Intensivos (UCI) hospitalaria. Una UCI es un espacio sobredeterminado y concreto, bien limitado espacialmente y cuyo origen y arqueología puede trazarse también con detalle. En primer lugar, una UCI está inserta en la estructura funcional y simbólica que representa la institución hospitalaria, en primera instancia, y en los servicios de salud pública -con sus consiguientes compromisos ético-políticos y económicos-, en segunda. Hacia dentro, la UCI es un espacio en el que convergen la más sofisticada y aparatosa tecnología con los saberes prácticos y habilidades sociales más enraizados en la naturaleza humana, todo ello girando alrededor de la enfermedad y la muerte. Convoca la UCI, al mismo tiempo, formas de organización social y laboral fuertemente institucionalizadas y jerarquizadas con modelos de micro-interacción social espontánea e impredecible. Derechos y deberes, estructuras de poder, intereses económicos y académicos, las expectativas diversas de cada colectivo, sentimientos y temores, cargan y diversifican hasta el infinito las representaciones e imágenes que con relación a este pequeño espacio circulan permanentemente en torno a él.

La IC. necesita de objetos de investigación sumamente densos, sobredeterminados y concretos, con capacidad suficiente para excitar el conjunto fuerzas psicosociales que operan en un determinado espacio-tiempo social hasta hacerlas manifiestas y visibles, y por tanto investigables ${ }^{8}$.

\footnotetext{
${ }^{8}$ Estas afirmaciones, sin embargo, no presuponen un objetivismo naturalista, por completo fuera de nuestra posición, que asume las aportaciones del constructivismo y de la más reciente sociología del conocimiento (Cfr. Castro, M. y Castro. L., 2001, op. cít.)
} 


\section{EL PROBLEMA DE LA REPRESENTATIVIDAD DE LAS CONCLUSIONES EN LOS ESTUDIOS CUALITATIVOS 9}

\subsection{La representatividad en la investigación social cuantitativa o distributiva}

La investigación inferencial representa el reto de predicar de muchos a partir del estudio de sólo unos pocos. Este esfuerzo ha sido abordado por la investigación social de la mano de los modelos estadísticos y de la teoría de la probabilidad, al igual que se ha hecho en las ciencias naturales. Para que las conclusiones obtenidas del estudio de una muestra puedan extrapolarse a la población que representa deben cumplirse una serie de exigentes requisitos. Estos, junto con otras consideraciones, constituyen lo que se denomina teoría de muestras, y su cumplimiento es del todo indispensable para poder hablar de validez externa en una investigación (García Ferrando, 1986; Alvira, 1986; Blalock, 1986).

Resulta inevitable, pues, que al hablar de representatividad de las conclusiones de un estudio cualitativo se nos aparezca como horizonte de comparación esta misma cuestión en el seno de la investigación social no cualitativa o, si se prefiere, cuantitativa. Resulta frecuente y lamentable comprobar cómo esta cuestión se zanja de manera confusa, cuando no errónea, en muchos textos de investigación social aplicada ${ }^{10}$. Así ocurre cuando la investigación cualitativa se presenta como una suerte de investigación exploratoria, poco o nada sistemática y carente de rigor científico, o cuando se la concibe, a lo sumo, como una práctica orientada a la generación de hipótesis en el marco de un todo vale metodológico. Es bien cierto que la investigación cualitativa puede realizar tareas exploratorias y heurísticas con gran eficacia; sin embargo, la investigación cualitativa puede abordar también, y lo hace a diario, objetivos explicativos 11 más precisos y ambiciosos. En todos esos casos, la investigación cualitativa se enfrenta a la producción de un conocimiento inferencial, que partiendo del estudio de pequeñas muestras de población ambiciona afirmar sus descubrimientos más allá del grupo de individuos estudiados -aunque la particular lógica de la investigación cualitativa imponga límites estrictos al alcance de estas inferencias-.

\footnotetext{
${ }^{9}$ Como advertirá enseguida el lector familiarizado con la literatura cualitativa, las reflexiones que siguen son deudoras en su esencia de los trabajos de J. Ibañez y de lo que podría denominarse «escuela cualitativista de Madrid». Esperamos que nuestra exposición ayude a sistematizar y completar las fundamentales aportaciones de estos autores, con los que tenemos una cuantiosa deuda teórica.

10 Particularmente en la literatura de investigación comercial y publicitaria, donde esta cuestión se despacha con notable ligereza.

11 La expresión objetivos explicativos se utiliza en su sentido epistemológico más habitual, es decir, haciendo referencia a la búsqueda de relaciones de dependencia entre variables o grupos de variables que sirvan para predecir, aunque sea de modo orientativo, la evolución del fenómeno estudiado o las posibles alteraciones del modelo o estructura promovidas por la varianza de algún elemento estructural. Ocurre esto, por ejemplo, cuando intentamos explicar la aceptación o rechazo que ha manifestado un sector del electorado ante una campaña publicitaria de partido X, localizando sus puntos fuertes y sus frenos, e intentamos sugerir una reorientación del mensaje o la forma comunicativa en orden a superar las barreras encontradas u optimizar los resultados.
} 
Pero volvamos ahora al modelo estadístico-distributivo 12 y sus conceptos de muestra y representatividad. Una muestra es un conjunto de individuos extraídos al azar de otro conjunto mayor -población- al cual representan. Si la muestra ha sido obtenida convenientemente, los resultados de su estudio descriptivo podrán ser extrapolados a la población que representa. Esta proyección supone un proceso de inferencia lógica fundado probabilísticamente. Pero, ¿cómo se determina cuantitativa y cualitativamente ese muestra?, ¿cuántos y cuáles individuos deben seleccionarse?

Desde un punto de vista cuantitativo, el tamaño muestral se determina a partir de la ley de los grandes números y de la teoría de probabilidades, que permiten establecer cuántos individuos son necesanos para representar una población de tamaño conocido con un margen de error también conocido (García Ferrando, 1989; Alvira, 1986; Blalock,1986).

Más interesante para nosotros es reflexionar sobre las condiciones cualitativas que el modelo estadístico impone a la muestra. Cuatro principios configuran la naturaleza de la muestra:

Todos los individuos deben tener idéntica probabilidad de ser seleccionados, es decir, debe darse una real equiprobabilidad de las unidades muestrales que elimine el sesgo producido por una mayor accesibilidad de unas unidades frente a otras.

Cada individuo debe ser independiente de los demás, y su concurrencia a la muestra debe constituir un suceso también independiente, de suerte que la selección de una u otra unidad no sesgue las posibilidades de ninguna otra.

Los individuos son seleccionados al azar, lo cual garantiza la primera condición exigida.

No existe reflexividad, es decir, la unidad muestral es accesible a la observación tal y cómo es, de modo que su selección no altera su naturaleza.

Resulta evidente, al recordar estos compromisos ontológico-epistemológi$\cos$, el origen físico-mecánico y positivista de la conceptualización que funda el razonamiento y el modelo estadísticos. Cada unidad muestral es concebida, últimamente, como una partícula elemental, independiente y heterogénea, puramente pasiva, que aguarda impasible el azar de su selección (Arribas Macho, J. M., 1998 , pp. 86 y 94).

En el modelo estadístico, estos principios, aplicados a las entidades abstractas que son las unidades muestrales, en unión a los criterios estrictamente cuantitativos señalados anteriormente, permiten afirmar, para un determinado margen de error, que la información obtenida de la muestra puede ser proyectada a la población en su totalidad. Sin embargo, lo que resulta fundamentado para el modelo estadístico-abstracto, resulta sumamente comprometido para su aplicación a la conducta humana significativa. La investigación cuantitativa es, muchas veces, un gigante con pies de barro. Y ello tanto por motivos estrictamente operativos y de aplicación (diseño y aplicación de los cuestionarios, confección de registros de observación, sesgos en el trabajo de los entrevistadores y observado-

12 Para una aclaración de los térmminos cualitativo y distributivo, Ibañez, 1979, 1985; también Castro, M. y Castro, L. Ibídem. 
res, sustitución del registro de hechos por el registro de opiniones...; cfr. Ortí, 1986), como por razones estructurales insalvables (irreductibilidad del lenguaje a su función denotativa, sesgo ideológico en el diseño de los cuestionarios, reflexividad... (Ortí, 1986).

Pero no es este el momento de hacer una crítica al uso de la estadística en las ciencias sociales, ni mucho menos pretender fundar la legitimidad de la investigación cualitativa en una deslegitimación de la investigación cuantitativa (Camarero, L. A. y del Val Cid, C., 1999). Es ese un camino equivocado 13.

Como ha señalado Ibáñez (1979; 1985), el modelo estadístico da lugar a la formación de muestras bajo el principio de isomorfía. Dos grupos son isomórfi$\cos$ si tienen, esencialmente, la misma estructura (Clapham, 1992). Entre ellos existe una aplicación biunívoca, que relaciona cada término con su imagen, y, para determinado par de operadores, el resultado de operar dos orígenes con el resultado de operar sus imágenes. Una muestra construida conforme al modelo estadístico mantiene una relación isomórfica con la población que representa. Esto significa, al menos idealmente, que la muestra reproduce como un microuniverso el conjunto de todas las clases de elementos presentes en el origen, así como sus relaciones y proporciones básicas. Una muestra así elaborada constituye una representación por extensión y exhaustividad de la población original.

Conviene retener estos conceptos para comprender en su singularidad el tipo de representatividad propia de la investigación cualitativa, pues, en buena medida, ésta se funda en principios alternativos a los que acabamos de exponer.

\subsection{Las condiciones de posibilidad de una representatividad diferente de la representatividad estadística}

Como ya se ha señalado, en una parte de la literatura de técnicas y métodos de investigación social (Cfr. Ortega Martinez, 1990; Grande Esteban y Abascal Fernandez, 1999; Soler Pujals, 1991; 1997; Aaker y Day, 1989; Gordon y Langmaid, 1988; Sarabia Sánchez, 1999; Hague y Jackson, 1994), la investigación cualitativa se describe como un tipo de estudio en el que no es posible extrapolar resultados a la población de referencia; es decir, se da por supuesta la imposibilidad de inferir más allá de la muestra analizada cualquier información.

Evidentemente, quienes así se expresan lo hacen desde el punto de vista cuantitativo. No cabe duda de que los estudios cualitativos no manejan muestras de individuos u cualquier otra unidad muestral que cumplan con las exigencias cuantitativas y cualitativas que hemos descrito en la sección anterior. Las mиеstras utilizadas en este tipo de estudios son pequeñas, al tiempo que las unidades muestrales no han sido seleccionadas aleatoriamente. Por otra parte, el concepto de población, en muchos casos, exige una precisa matización.

Algunos autores se refieren a ese tipo de muestreo como no estadístico e intencional (García Ferrando, 1986). Sin embargo, no resulta sencillo encontrar

13 Para la articulación de las perspectivas cualitativa y cuantitativa: Ibáñez, 1979; 1985; Ortí, 1986, 1994; Bericat, 1998; Conde, 1999; Castro y Castro, Ibídem. 
una exposición razonada de $a$ ) por qué los estudios cualitativos no siguen los criterios de representatividad estadística, $b$ ) si existe algún otro modelo teórico y metodológico que pueda garantizar una cierta representatividad a las conclusiones de esos estudios y $d$ ) en caso de existir, qué fundamentos ontológico-epistemológicos y teóricos le dan cobertura ${ }^{14}$.

A continuación vamos a intentar responder a estas cuestiones. Algunas de las ideas fundamentales que vamos a exponer pueden encontrarse en otros textos (Ibáñez, 1979, 1985; Ortí, 1986, 1994; Alonso, 1998; Delgado y Gutiérrez, 1994), sin embargo creemos que nuestra exposición puede aportar una mayor sistemacidad a las mismas, así como complementar algunos lagunas presentes en la literatura.

Como ha afirmado Ibáñez (1979), la lógica de la inferencia en la investigación cualitativa se sostiene en un conjunto de principios alternativos a los del modelo de inferencia cuantitativo. Así, las muestras con las que se trabaja en un estudio cualitativo constituyen un modo de representación homomórfico. Un homomorfismo es una aplicación entre dos estructuras algebraicas del mismo tipo, pero a diferencia de lo que ocurre en la relación isomórfica, la relación entre estructuras no es de identidad. Es decir, la muestra no reproduce en su seno la totalidad de relaciones y estructuras presentes en la población sino sólo una parte de ellas -epimorfismo (Clapham, 1992 )-. Pero, ¿cuáles? La «representatividad cualitativa» consiste en la reproducción en la muestra de aquellas relaciones y estructuras pertinentes para una comprensión de la organización estructural de la población-objeto. Conocer la organización estructural de una realidad -por ejemplo, la organización estructural de un grupo social- exige reproducir experimentalmente dicha estructura en sus elementos y relaciones pertinentes.

De este modo, frente a la isomorfía y a la representación exhaustiva y por extensión del modelo cuantitativo, nos encontramos con una relación homomórfica y una representación intensiva y por pertinencia en el modelo cualitativo.

Un ejemplo puede ayudarnos a aclarar las cosas. Al investigar la organización y estructura de una UCI de un gran hospital público, en sus dimensiones físicas, funcional, simbólico-ideológica e imaginaria (Castro, M. y Castro, L. Cfr. supra nota 1), no pueden tenerse en cuenta, uno a uno, todos los actos médicos realizados por multitud de profesionales, ni pueden considerarse todos los ingresos, es decir, los pacientes -cientos cada año-, amén de sus familias. El estudio de una organización como ésta y, en ella, las particulares perspectivas del staff y de los pacientes en torno a su funcionamiento, exige un trabajo de reducción de la complejidad que salve lo esencial y elimine lo accesorio o circunstancial. La

14 Cómo abordar el problema de la representatividad cualitativa es algo que puede afrontarse a partir de varios presupuestos. Sin menoscabo de otras aproximaciones, nosotros hemos optado por hacerlo desde la óptica estructuralista, cuyas aportaciones al campo del análisis de textos ha sido fundamental no sólo para la crítica literaria sino también para una crítica de la cultura. No cabe duda de que esta cuestión está enlazada con la discusión sobre la validez de los estudios cualitativos. Sin ambargo, aunque fundamental, ese debate suele traducirse en una galopante inflación de conceptos alternativos (Cfr. Ruiz Olabuénaga, 1996:83 ss) que oscurecen más que aclaran. Por nuestra parte, preferimos remitirnos a una tradición con suficiente arraigo y proximidad epistémica a nuestro propios criterio para abordar el asunto de la representatividad. 
investigación cualitativa afronta esta dificultad determinando el conjunto de marcadores estructurales que vertebran ese espacio-tiempo social y cuya combinación da lugar a un conjunto de perfiles estructurales específicos. Estos perfiles no se identifican con individuos concretos, sino con clases de individuos definidos por su posición en la red de relaciones de la estructura/institución que se estudia. El análisis de estos tipos sociales y discursivos constituye el procedimiento esencial de la investigacion.

Por ejemplo, para seleccionar la muestra de pacientes con la que se habría de trabajar se comenzó por consultar a los profesionales. Estos ofrecieron una tipología de la morbilidad organizada en torno a los conceptos de $a$ ) etiología, $b$ ) esfuerzo terapéutico necesario, $c$ ) duración de la estancia, $d$ ) pronóstico y $e$ ) origen-destino dentro del organigrama del hospital. En segundo lugar, algunas entrevistas exploratorias e informales a familiares de enfermos y a enfermos recuperados mostraron que la percepción de éstos difería categorialmente de forma significativa de la del staff al subrayar como hecho fundamental el ingreso, ya sea como fase previsible de una secuencia mayor -en una enfermedad crónica o terminal- o como ruptura de la normalidad y sobrevenida por un accidente, vg.: un infarto. Por último, el análisis de algunas estadísticas del servicio permitió valorar en términos distributivos las distintas categorías del modelo que emergía. El resultado de estas pesquisas exploratorias permitió reducir el azaroso y variadísimo universo de ingresos en el servicio de la UCI a los siguientes tipos:

\begin{tabular}{|c|c|c|c|c|c|c|c|c|}
\hline \multirow{2}{*}{$\begin{array}{l}\text { Grado de esfuerzo } \\
\text { terapéutico/Especialidad } \\
\text { médica (= causa ingreso) }\end{array}$} & \multicolumn{4}{|c|}{$\begin{array}{c}\text { Ingreso } \\
\text { sobrevenido }\end{array}$} & \multicolumn{4}{|c|}{$\begin{array}{c}\text { Ingreso en fase } \\
\text { aguda y/o terminal }\end{array}$} \\
\hline & E.1 & E. 2 & E. 3 & E.4 & E.1 & E.2 & E.3 & E.4 \\
\hline \multicolumn{9}{|l|}{ Alto esfuerzo terapéutico } \\
\hline \multicolumn{9}{|l|}{ Bajo esfuerzo terapéutico } \\
\hline & \multicolumn{4}{|c|}{ Gradiente de fatalidad } & \multicolumn{4}{|c|}{ Gradiente de fatalidad } \\
\hline
\end{tabular}

Nota. Sólo se recogen los rasgos más relevantes, pero no únicos. Otros como la edad, la clase social, la duración o la reiteración del ingreso no se recogen en esta tabla, aunque son de importancia en el modelo completo.

En esta tabla, cada una de las celdas vacías representa un tipo de enfermo y, hasta cierto punto, un tipo de perspectiva y discurso. En su conjunto, la perspectiva de los pacientes, en general, tiende a cerrarse sobre sí misma y a diferenciarse de otras, por ejemplo la del staff Pero en su interior, la categoría enfermo encierra una heterogeneidad que debe ser registrada. Esta tabla, pues, representa un mapa de posiciones en la organización del campo de la enfermedad en la UCI y, al mismo tiempo, de las virtuales formas discursivas, en parte homogéneas, en parte heterogéneas, que les caracteriza en calidad de pacientes. La rentabilidad del modelo sólo quedará legitimada o rechazada al final del estudio por su rendi- 
miento heurístico y sólo entonces podrá valorarse cabalmente su pertinencia. Sin embargo, es esencial hacer un esfuerzo teórico-metodológico por narrar públicamente el proceso de elaboración del diseño y justificar provisionalmente las decisiones que se adoptan. Volveremos al ejemplo más adelante y en repetidas ocasiones.

Si lo anterior expresa el núcleo de la «lógica inferencial» cualitativa, se hace necesario desplegar ahora el conjunto de principios que lo fundan y dan sentido. A nuestro juicio, pueden reducirse a cuatro:

Frente a la orientación individualista/atomista que caracteriza a la perspectiva estadística, la investigación cualitativa asume la representación de lo social como estructura(s) y sistema. Sin que ello deba suponer la reducción del individuo a una mera posición estructural, pues la naturaleza de actor social del sujeto no puede/debe ser extirpada, la orientación cualitativa representa la realidad psicosocial como un conjunto de elementos -roles, conductas, expectativas, criterios, imágenes, opiniones...- organizados a partir de un sistema de relaciones dotado de una cierta estabilidad y objetividad -estructura-. Por ello, la mirada cualitativa (Alonso, 1998) se orienta a los individuos como entidades en las que converge la exterioridad social, estable, homogeneizante y predecible y la interioridad subjetiva, azarosa, individualizante e irreductible. En este sentido, creemos que se puede afirmar que para la investigación cualitativa la verdadera unidad muestral no es el individuo, sino lo que podemos denominar una "posición estructural». Estas posiciones estructurales vienen definidas por un conjunto de rasgos que adquieren su condición de pertinencia con relación al objeto de estudio que se considere y bajo ciertos supuestos teóricos y metodológicos que deben ser explicitados en cada investigación. Así, al diseñar un estudio cualitativo el investigador debe elaborar un índice de criterios estructurales de pertinencia que permitan recortar en la intricada estructura psicosocial de la población general aquellas posiciones estructurales que van a ser consideradas y para las cuales el estudio pretende inferir cierta información. La determinación precisa e intensiva de esos rasgos y posiciones estructurales permitirá determinar su posicionamiento ante el objeto de estudio o cualquier otro objetivo informacional que se pretenda.

Así, en el ejemplo anterior, el universo de enfermos/ingresos de la UCI ha quedado reducido a un número limitado y manejable de posiciones estructurales: enfermos en fase terminal/aguda oncológicos que necesitan un alto esfuerzo terapéutico, enfermos de ingreso sobrevenido con patología cardiológica y bajo esfuerzo terapéutico, etc. Como hemos visto, éstas surgen de la combinación de un pequeño número de rasgos fundamentales (grado de esfuerzo terapéutico, causa ingreso, pronóstico, ...) cuya relevancia se ha puesto de manifiesto en una fase exploratoria. Estas posiciones estructurales funcionan como grandes núcleos o nodos que organizan el entramado de relaciones sociales y discursivas dentro del campo que se analiza. No obstante, no debe engañarnos la simplicidad del modelo, pues la realidad desborda continuamente estas aproximaciones reductivistas; así, por ejemplo, el discurso de los médicos se ha manifestado sumamente fraccionado y, aunque resulte homogéneo en algunos elementos, contiene en su interior poderosas fuerzas (jerarquía profesional, especialidad terapéutica, 
orientación humanista vs. orientación técnica, perfil investigador, edad, sexo,...), que tienden a diversificar en múltiples direcciones las variantes discursivas. La selección de rasgos pertinentes, conviene insistir en ello, debe fundamentarse en criterios teórico-metodológicos explícitos, aunque su legitimidad quede diferida, últimamente, hasta la finalización del estudio.

Frente a la independencia y heterogeneidad con que el modelo estadístico representa a los individuos/unidades muestrales con los que trabaja, la orientación cualitativa juega con el concepto contrario: homogeneidad. La posibilidad de proyectar algún tipo de información a partir de una pequeña muestra de individuos/unidades muestrales a un conjunto mayor descansa en la hipótesis de la homogeneidad interna de una posición estructural. Cuando definimos una determinada posición con precisión e intensidad (es decir, han sido seleccionadas todos y cada uno de los rasgos pertinentes) podemos suponer que, para el objeto de investigación dado -cuya singularidad ha orientado la selección de los rasgos y la construcción de la posición estructural-, los individuos adscritos a esa posición van a manifestar una esencial unidad de criterio y posicionamiento. Esa homogeneidad no debe ser entendida, es necesario insistir en ello, como una replicación mecánica y clónica de un universo de significaciones, conductas o imágenes que domina a los individuos y se manifiesta autoritariamente a través de ellos; la homogeneidad de la que hablamos es el resultado de una constante recreación y reproducción de las representaciones sociales que, simultáneamente, son fruto del peso cosificado de la exterioridad social y de los intereses pragmáticos y situacionales de los individuos. Precisamente por ello, la representatividad de las conclusiones de un estudio cualitativo es posible en el seno de un proceso de inferencia que conjugue $a$ ) la proyección de lo descubierto en la posición estructural correspondiente a la población con $b$ ) la contextualidad que impone la dimensión situacional de toda investigación cualitativa. No sería correcto, sin embargo, cerrar este principio de primacía de la homogeneidad sin hacer ver la necesidad de incorporar la diferencia también; aunque luego se discutirá este asunto con más precisión, debemos afirmar la necesidad de incorporar una cierta heterogeneidad en el seno de las muestras, pues sin ella la dinámica de producción del discurso social sería imposible.

En nuestro ejemplo, la homogeneidad de la que hablamos se manifiesta en la unidad de criterio y posicionamiento, de percepción y representación, que caracteriza a cada posición estructural (con las salvedades ya señaladas). En nuestro caso, los distintos tipos de pacientes comparten una buena porción de su sistema de representaciones con relación a su vivencia como enfermos y a la organización/institución UCI; sin embargo, cada posición aporta una cierta heterogeneidad, una cierta diferencia, a su vez compartida con los que están en el seno de esa posición. A todo ello hay que añadir la irreductible variabilidad fruto de circunstancias concretas, situacionales y biográficas, que devuelven al sujeto su naturaleza de actor. Así, por ejemplo, algunos enfermos perciben el sobrecogedor marco tecnológico-terapéutico de la UCI como un magnífico -a la vez que incomprensible- esfuerzo a disposición de la esperanza de mantener una vida -amenazada, quizá, por un inesperado accidente-, mientras que, para otros, cada aparato, cada vía, cada conexión, cada sustancia administrada es un acto de tortura y 
una innecesaria violación de su dignidad -como ocurre, a veces, en enfermos terminales y crónicos. Ahora bien, esta polarización se ve transgredida no pocas veces, como por ejemplo en pacientes con fuertes creencias religiosas que modulan la percepción acerca de su propio proceso, en una u otra dirección.

Los métodos y técnicas cualitativos de investigación social han sido definidos, con razón, como técnicas de registro y análisis de discursos sociales (Alonso, 1998) ${ }^{15}$. La investigación social cualitativa está orientada al registro e interpretación de los discursos sociales adscritos a las distintas posiciones estructurales. Dichos discursos funcionan como formas estereotipadas de representar lo real y de categorizar la conducta propia y ajena, dotadas de cierta estabilidad, que contienen el conjunto de las representaciones sociales características de un grupo social con relación a un determinado estímulo u objeto. Lo que se produce en el seno de un grupo de discusión es, precisamente, el acceso al discurso social que constituye al grupo en cuestión; dicho acceso se produce a través del habla de los participantes, es decir, a través del habla tomada como texto. Así, mientras la manifestación empírica de la conversación puede ser tenida como su actualización, el discurso puede ser concebido como la competencia del hablante -en términos chomskyanos-. Los discursos, pues, son el correlato expresivo y сотиnicativo de la homogeneidad característica de una posición socioestructural -con relación a un objeto dado-, y su análisis es la condición de posibilidad de la exploración del universo de representaciones que constituyen el imaginario social del grupo. De esta manera, vemos cómo se encadena de modo coherente la secuencia 1. posición estructural + contexto situacional, 2 . homogeneidad + heterogeneidad, 3. manifestación discursiva + producción empírica.

El último principio sobre el que descansa la representatividad estructural nos sitúa en un plano de análisis semiótico e informacional del que depende el criterio cuantitativo de clausura muestral. Según hemos afirmado, la determinación de posiciones estructurales densa y precisamente descritas -con relación a un objeto dado- hace posible la aparición de un grupo homogéneo de individuos cuya habla, convenientemente inducida y registrada a través de las técnicas apropiadas, nos dará acceso a los discursos sociales adscritos a esos perfiles sociales. Dichos discursos, a su vez, nos proporcionarán el acceso a los universos simbólicos, ideológicos e imaginarios de los grupos, combinados con los intereses concretos de los actores en situación. Pero, ¿cuándo podemos tener la certeza de que nuestra información es suficiente?, ¿cuándo habré de dejar de entrevistar o leer documentos y transcripciones?, ¿cuándo estará completo mi modelo interpretativo? La determinación del tamaño de la muestra de individuos o del corpus documental que será analizado no puede hacerse, como en el modelo estadístico, $a$ priori. Para afrontar esta cuestión es necesario rescatar las aportaciones de la semiótica, particularmente los trabajos de Greimas (1987), con relación a la

15 La noción de discurso social es muy importante para la investigación cualitativa. Sin embargo, puede introducir un sesgo lingüístico que hay que vigilar. Como ya advertimos en otro lugar (Castro y Castro Ibídem) lo discursivo no puede agotar el campo de lo imaginario, de modo que aunque el acceso a los sistemas de representación y a los imaginarios sociales esté mediado lingüísticamente, no podemos pensar que discurso e imagen (fantasias diurnas, sueños...) sean realidades ontológicamente homogéneas. 
determinación del corpus para el análisis semiótico de textos. La legitimidad de éstas descansa en la naturaleza lingüística y discursiva del material empírico con el que trabaja, en último término, el investigador cualitativo, y en sus propiedades semióticas y comunicacionales, de suerte que el cierre muestral se adopta mirando a la producción discursiva de los individuos seleccionados antes que a cualquier otro criterio. En síntesis, podemos decir que cuando la producción lingüística empírica registrada resulte redundante en sus contenidos y manifestaciones estructurales, es decir, cuando haya sido posible elaborar un modelo discursivo que resista la contrastación con nuevas aportaciones de material empírico sin sufrir alteraciones significativas, entonces podremos finalizar el escrutinio, dando por cerrado el proceso de registro de información. Sin embargo, como veremos, este tema es algo más complejo y espinoso de lo que acabamos de manifestar.

En su Semántica Estructural, Greimas, al tratar de los procedimientos de descripción de la significación comienza por determinar las condiciones de formación del corpus que va a ser sometido a análisis. En suma, se trata de analizar qué condiciones debe cumplir una muestra lingüística -por ejemplo, literaria- para que pueda ser tenida como suficientemente representativa de una producción lingüística mayor, a la cual representa -por ejemplo, una parte de la obra literaria de Galdós como corpus representativo para la descripción de la significación de la obra total del autor-. Por corpus, afirma Greimas, debe entenderse «un conjunto de mensajes constituido con vistas a la descripción de un modelo lingüístico» (Ibídem). El corpus funciona así como un microuniverso semántico en el que se contienen las isotopías pertinentes, cuyo descubrimiento alienta la investigación. Para que un corpus cumpla su finalidad deben ponerse en práctica ciertas precauciones metodológicas que minimicen la parte de subjetividad y azar que permanecen siempre como resto. Estas condiciones son las siguientes: el corpus debe ser representativo, exhaustivo y homogéneo (Greimas, Ibídem).

La representatividad «puede definirse como la relación hipotáctica que va de la parte que es el corpus a la totalidad del discurso, efectivamente realizado o simplemente posible, que aquél subentiende... Lo que permite sostener que el corpus, aunque sea parcial, pueda ser representativo son los rasgos fundamentales del funcionamiento del discurso, a los que se han dado los nombres de redundancia y clausura» (Ibídem). La redundancia no es, sino, la iteratividad característica del dicurso «que tiende a cerrarse sobre sí mismo» (Ibídem), por lo que el modo de ser del discurso lleva en sí mismo las condiciones de posibilidad de su representatividad; la clausura hace referencia al efecto de cierre que se consigue al quedar saturados los contenidos figurativos, las formas estructurales o los esquemas narrativos que brotan del análisis de la sustancia expresiva.

Pero además de representativo, el corpus ha de ser exhaustivo. «La exhaustividad ha de concebirse, a su vez, como la adecuación del modelo que se ha de construir a la totalidad de sus elementos implícitamente contenidos en el corpus. Si el corpus es excesivamente grande, parece lógico buscar algún procedimiento que economice esfuerzos y que permita sustituir la exhaustividad descrita por una aproximación más abreviada aunque con garantías. A este respecto, Greimas propone 1. en una primera fase, la descripción se haría utilizando solamente un 
fragmento del corpus y construyendo a partir de él un modelo con valor puramente operatorio y 2. en una segunda fase se procedería a la verificación del modelo provisional bien por saturación del modelo (Propp, Lévi-Strauss), comparándolo sistemáticamente con el resto del corpus, bien por sondeos (Dubois), es decir, eligiendo aleatoriamente ciertas partes del corpus y comparando el modelo provisional con lo que se encuentre en esos segmentos.

Por último, la homogeneidad hace referencia a la necesidad de que el corpus remita, realmente, a un modelo lingüístico dotado de unidad semántica -pues la heterogeneidad no es reductible a un modelo de isotopías que vertebren su significación-. Este problema, como señala Greimas, se presenta con mayor dificultad en los corpus colectivos, cuya unidad requiere una previa fundamentación, pues en los individuales cabe pensar en que la unidad psicosocial que es el sujeto garantiza una unidad en la manifestación discursiva.

Trataremos ahora de situar estas categorías de análisis y estos requerimientos metodológicos en nuestro campo de trabajo, traduciéndolos a conceptos y procedimientos teórico-metodológicos válidos para la $I C$. Por corpus podemos entender un conjunto de manifestaciones comunicativas de un determinado número de individuos $-\mathrm{O}$ un conjunto documental-, registradas convenientemente, que van a ser utilizadas como muestra del conjunto virtual de todas las posibles manifestaciones que dichos individuos, y en último término su grupo o perfil social -definido en términos estructurales-, podrían manifestar con relación a un estímulo u objeto determinado. El propósito de la selección de ese corpus es acceder, a partir de su análisis, a las posibles formas discursivas estereotipadas, típicas y tópicas, que contienen las representaciones del imaginario social de tal grupo con relación con tal objeto.

La naturaleza linguiística -aunque no sólo lingüística- del corpus -transcripciones de entrevistas y grupos, documentos personales, artículos o publicaciones, narraciones biográficas...- hace posible someter el material empírico a los criterios y exigencias expuestas por Greimas. La representatividad ha de entenderse en este contexto como la potencialidad del corpus empírico para reproducir en su seno las estructuras discursivas y las isotopías semánticas del discurso virtual que, en un sentido arquetípico, constituye e instituye al grupo/posición estructural. Por ejemplo, al descubrir los ejes fundamentales que vertebran el discurso de los médicos frente al de los pacientes o al de las enfermeras aun sabiendo que cada uno de esos discursos encierra una diversidad desbordante.

La redundancia y la clausura, indicadores de la representatividad, se interpretan en nuestro trabajo como el hecho verificable de la reiteración creciente del material empírico. Al analizar el discurso de los médicos vemos aparecer enseguida algunos conceptos, relaciones, criterios, opiniones, imágenes, ... que tienden a reiterarse y a precipitar como constituyentes subyacentes de la variabilidad empírica del habla, manifestándose como su estructura profunda-cuya interpretación remite, a su vez, a un sistema de fuerzas y estructuras sociales-. Al avanzar en el análisis del corpus, la redundancia se hace cada vez más ostensible con relación a esas estructuras e invariantes discursivas, de modo que las aportaciones de nuevo material empírico -nuevas entrevistas, nuevos documentos...- no producen modificaciones estructurales relevantes. Cuando esto ocurre así, pode- 
mos sentirnos legitimados a clausurar nuestro modelo de representación e interpretación del discurso.

La exhaustividad señala la necesidad de que todas las categorías y rasgos pertinentes para el estudio -las determinadas a priori, pero también las emergentes a posteriori- hayan sido examinadas en el corpus y representadas en el modelo de interpretación, así como que sus atributos, dimensiones y relaciones hayan sido desplegados en todas sus posibilidades pertinentes. Por ejemplo, el análisis del discurso de los enfermos, como hemos visto, exige fragmentar esta posición discursiva en otras varias; éstas aparecen como resultado de la intervención combinada de un conjunto de rasgos cuyo efecto es el surgimiento de una red de posiciones parcialmente diferentes. Al recoger el material empírico y analizarlo, la exhaustividad se traduce en la saturación de cada una de esas posiciones y rasgos que ha de quedar representada en el modelo interpretativo; se trata de una saturación estructural, pues lo que se agota en el modelo es la diversidad de posiciones estructurales y discursivas, nunca los individuos adscritos a ellas ni las variaciones empíricas del habla, inagotables por definición y presentes en exceso.

Por último, con relación a la cuestión de la validez de los corpus colectivos debemos recordar lo que hemos expuesto más arriba acerca de la homogeneidad que caracteriza, desde el punto de vista discursivo, a una determinada posición estructural-siempre con relación a un determinado objeto-. La homogeneidad discursiva quedaría fundada en la homogeneidad psicosocial derivada de los postulados estructurales que hemos venido defendiendo como fundamentos de toda $I C$. - -y que no deben anular, en modo alguno la identidad del individuo como actor social, sino que la incorpora como diferencia y contextualidad-.

Concluimos esta sección haciendo un mínimo balance acerca de la cuestión de la representatividad en los estudios cualitativos. Todo lo expuesto apunta a la existencia de un modelo alternativo al modelo estadístico con capacidad para fundar, razonablemente, un tipo de investigación inferencial, al que podemos denominar cualitativo o estructural. Este modelo construye la representatividad de las conclusiones de un estudio cualitativo sobre consolidados principios psicosociales y semióticos. Sin embargo, como se ha señalado en la primera sección de este artículo, queda un largo camino por recorrer en relación con los procesos y criterios de operacionalización del modelo metodológico. Resulta imprescindible afrontar esta tarea de mayor concreción procedimental si queremos convertir los principios teóricos en diseños de investigación comunicables, replicables y discutibles en la comunidad científica. Las siguientes páginas son una pequeña contribución a este propósito.

\section{LA DETERMINACIÓN DE LAS POSICIONES ESTRUCTURALES}

En la sección anterior se han expuesto los fundamentos de una representatividad estructural, no estadística. Como se ha puesto de manifiesto, dicha representatividad descansa sobre la hipótesis metodológica de la homogeneidad psicosocial y discursiva que caracteriza, como rasgo interno, a una determinada posición estructural con relación a un objeto dado. 
En esta sección intentaremos concretar, hasta donde es posible, la naturaleza de esas posiciones estructurales y los procedimientos a seguir para su determinación.

Cada posición social es, por así decir, un recorte en el entramado estructural del espacio-tiempo social. Habitualmente, estas posiciones estructurales agrupan a individuos con perfiles psicosociales homogéneos, aunque nada obsta para que una posición estructural pueda referirse a otra clase de realidades (como por ejemplo, a publicaciones periódicas, discursos políticos, marcas comerciales, productos o cualquier clase de objeto físico o simbólico...). El contenido concreto que «rellena» esa posición puede variar y, en todo caso, sólo puede ser determinado a posteriori.

Existen infinitas posiciones estructurales, pues el número de rasgos que pueden utilizarse para su construcción es, asimismo, innumerable. Una posición social es el resultado de combinar un conjunto de rasgos seleccionados conforme a criterios de pertinencia teórica y metodológica. El conjunto de rasgos pertinentes sólo puede ser determinado ad hoc y su selección depende, en primer lugar, del objeto de estudio o fenómeno que se esté investigando. Lo que resulta pertinente en un estudio puede no serlo en absoluto en otro, por lo que no resulta posible «listar»a priori un índice de rasgos pertinentes.

Sin embargo, sí es posible y necesario ordenar los procedimientos para la construcción de estas posiciones estructurales y, por tanto, de la muestra a analizar. Concretamente, se hace necesario una reflexión que organice el universo de rasgos o características ofreciendo criterios selectivos que faciliten y orienten la confección de perfiles específicos.

A continuación, esbozaremos estas reflexiones organizadas en dos apartados: a) el objeto de estudio y la selección de la muestra y b) análisis de rasgos pertinentes.

\subsection{El objeto de estudio y la selección de la muestra}

El objeto de estudio es el primer factor que ordena el campo social y hace emerger las estructuras psicosociales pertinentes. La realidad social está fuertemente entreverada y en ella operan multitud de fuerzas que tensionan su(s) estructura(s). Sin embargo, estas fuerzas y estructuras sociales sólo se hacen manifiestas ante objetos o estímulos que provocan y catalizan su emergencia. Metodológicamente no creemos acertado hablar de la estructura social, sino de estructuras sociales, accesibles sólo desde un estímulo u objeto de estudio. Es evidente que estas estructuras no poseen todas por igual la misma relevancia teórica y, mucho menos, práctica, pues generan asimetrías de muy diferentes consecuencias para los individuos que se ven arrastrados por ellas. Sin embargo, es necesario insistir en la dependencia metodológica y teórica que estamos señalando y que obliga al investigador a derivar su análisis de estructuras a partir de la acción ordenadora que el objeto induce en el campo social.

Por todo ello, sólo una correcta comprensión del objeto de estudio y una reflexión teórico-metodológica minuciosa acerca de él, podrán fundamentar con- 
venientemente el diseño de la investigación y, por ende, garantizar, al menos parcialmente, su éxito. A lo que hay que añadir las consideraciones hechas a este respecto en la sección segunda de este artículo.

\subsection{Análisis de rasgos pertinentes}

Como ya señalamos con anterioridad, son las circunstancias concretas de cada estudio y la naturaleza del objeto de investigación las que determinan, en cada caso, el listado de rasgos pertinentes. Son pertinentes aquellos rasgos que permiten comprender cómo se organiza estructuralmente un campo social determinado con relación a un objeto o estímulo de investigación, y cuya mutación origina cambios significativos en dicha organización. Por ejemplo, el rasgo «staff vs. paciente», que define el tipo de relación del individuo con la institución resulta pertinente para la descripción y comprensión de la organización UCI.

Toda investigación cualitativa -y últimamente toda investigación socialdebe incluir un proceso de discusión de rasgos, fundado teórica y metodológicamente, que ofrezca como resultado un modelo, más o menos complejo, de la organización estructural del campo social que se investiga. Dicho modelo es, simultáneamente, la condición de posibilidad de dicha investigación y una hipótesis que ha de ser testada.

A continuación intentaremos establecer algunos criterios que permitan afrontar el diseño de la muestra y la discusión de rasgos pertinentes con un cierto orden y rigor.

Desde el punto de vista de su naturaleza los rasgos pertinentes pueden ser clasificados en dos grandes grupos:

Rasgos (variables) sociodemográficos: son aquellos que permiten situar al individuo en la estructuras sociales y demográficas generales. Son variables sociodemográficas la edad, el sexo, la ocupación, la clase social, el nivel de renta, el grado de formación, etc.

Rasgos categoriales: son rasgos categoriales aquellos que definen una relación entre los individuos y el objeto de estudio o entre los individuos y las determinaciones situacionales concretas. En nuestra investigación sobre una UCI la lista de rasgos categoriales es muy extensa; por ejemplo, podemos citar: ocupación o relación con la UCI (médico, enfermero/a, celador, paciente...), tipo de enfermedad, pronóstico, duración del ingreso, etc.. Es evidente que este tipo de rasgos no puede ser determinado a priori pues cualquier rasgo, característica o atributo puede ser considerado rasgo categorial, y sólo la definición del objeto de estudio y de la situación concreta de análisis hace emerger esta singularidad. Así, tener canas puede ser un rasgo categorial fundamental en un estudio sobre productos de coloración para el cabello y resultar absurdo en una investigación sobre preferencias de los lectores de revistas de información general.

Ahora podemos señalar con más precisión que una posición estructural es el resultado de combinar un grupo de rasgos sociodemográficos y categoriales. El resultado de esta combinación debe ofrecernos un perfil social al que puedan ser adscritos «objetivamente» individuos reales -o cualquier otra clase de realidades, 
en su caso- cuyos discursos van a ser analizados. Por ejemplo, una posición estructural/discursiva puede quedar definida del siguiente modo: médicos intensivistas de ambos sexos, titulares, con más de quince años de experiencia y actitud favorable ante la limitación del esfuerzo terapéutico en enfermos terminales. La determinación de este perfil permite identificar por procedimientos objetivos a individuos concretos que puedan encarnarlo. Sin embargo, es fácil confundir esa combinación de rasgos con los procedimientos de «cruce» sistemático que tantas veces se practican en el análisis multivariante de la investigación cuantitativa. No se trata aquí de fabricar todas las posibles combinaciones a partir de un grupo de rasgos, representen éstos, o no, a sectores reales de la población. Lo que se persigue en la $I C$. es la determinación de aquellas posiciones estructurales verdaderamente relevantes para el estudio; éstas se objetivan a través de una mezcla de rasgos sociodemográficos y categoriales y, una vez definidos, actúan como nodos de la urdimbre social y focos productores de significados discursivos singulares y singularizantes.

Los rasgos categoriales pueden definirse operacionalmente de tres modos diferentes:

Rasgos categoriales factuales: son aquellos en los que la relación sujetoobjeto-situación se expresa a través de la determinación de un hecho. Por ejemplo, padecer una determinada enfermedad, haber perdido un familiar internado en la UCI durante el último año, etc.

Rasgos categoriales conductuales: son aquellos en los que la relación sujetoobjeto-situación se expresa mediante una conducta o su repetición, o una secuencia de comportamiento, como por ejemplo, un hábito. Por ejemplo, administrar habitualmente un determinado fármaco, informar al paciente de determinado modo acerca de su pronóstico, recomendar como norma la sedación del paciente en determinadas circunstancias terminales, etc.

Rasgos categoriales actitudinales: son aquellos en los que la relación sujetoobjeto-situación se expresa a través de una actitud. Por ejemplo, manifestar una actitud favorable/desfavorable a la intervención del criterio del paciente en la determinación del esfuerzo terapéutico, sentir rechazo por la eutanasia, etc.

Hay que hacer notar que esta tipología de rasgos se ve habitualmente excedida por la práctica de la investigación, resultando difícil precisar el tipo al que debe ajustarse la definición de un rasgo. Ocurre así, por ejemplo, cada vez que una variable sociodemográfica, por razón del objeto de estudio, se convierte en categorial. En nuestro estudio, la ocupación es a la vez sociodemográfica y categorial. Esta tipología, como cualquier otra, debe tomarse como un instrumento auxiliar y heurístico y no como norma.

Por último, los rasgos pertinentes pueden ser contemplados también desde la perspectiva de su incidencia «homogeneizante», o por el contrario, «diversificante». Hemos subrayado con insistencia que la representatividad de las conclusiones de un estudio cualitativo se funda, entre otros principios, en la homogeneidad intragrupo. Posiciones estructurales diferentes producen posiciones discursivas también diferentes, por lo que es sumamente importante perfilar con precisión cada uno de los nodos, marcando las diferencias que fundan sus singularidades. A este propósito resulta fundamental determinar el poder homogeneizante o 
diversificante de cada una de los rasgos -sociodemográficos y categoriales- que va ser introducida en la confección de la posición estructural. Una vez más resulta muy difícil poder hacer previsiones a priori con relación a esta fundamental cuestión. La dificultad estriba en que cada uno de los rasgos cobra significado y funcionalidad sólo en presencia del objeto de estudio, por lo que hemos de esperar a definirlo para discutir el papel que corresponde a cada una. Sin embargo, creemos posible hacer algunas precisiones que pueden tomarse como orientaciones razonables a este respecto, así como algunos criterios que permitan testar el papel de cada rasgo.

A este respecto, nos parece interesante por su rentabilidad heurística ordenar el campo de los rasgos pertinentes -tanto sociodemográficos como categorialesen dos polos: rasgos de oposición fuerte, altamente diversificadores, y rasgos de oposición débil, poco diversificadores. Los primeros serían aquellos que definen un nodo o lugar estructural por oposición a otro; su poder diversificador genera fuertes diferencias intergrupo, a la vez que lo homogeneiza ad intra. Los segundos generan asimetrías de menor incidencia, por lo que su inclusión sirve para introducir una cierta heterogeneidad dentro de una posición esencialmente homogénea. Cualquiera que conozca, por ejemplo, la técnica del grupo de discusión comprenderá enseguida la importancia de estas precisiones. Una vez más, es necesario insistir, aún a riesgo de reiterarnos, en la dificultad que se esconde tras una tipología de apariencia tan sencilla; en primer lugar, por que no es posible definir con precisión la incidencia de un rasgo hasta no conocer con detalle las circunstancias concretas del estudio y, en segundo lugar, por que, una vez conocidas éstas, se tratará de una estimación cuya legitimidad sólo podrá probarse, últimamente, en función del rendimiento que haya proporcionado su inclusión o eliminación en el modelo teórico-metodológico que sostiene la investigación.

Ibáñez (1979) ha subrayado el papel fuertemente diversificante que juega un pequeño conjunto de variables sociodemográficas básicas. Estas son el sexo, la edad, la clase social y el tipo de hábitat. Al señalar su poder dijerenciador lo que se afirma es que, para cada una de esas variables, pertenecer a uno u otro intervalo o valor supone posicionarse de modo significativamente distinto con relación al objeto de estudio, o si se prefiere, participar de sistemas de representación alternativos. Esto es lo que cabe pensar al juzgar a priori las más que probables y señaladas diferencias de posicionamiento, intereses y representación que se dan entre hombres y mujeres, entre jóvenes y adultos, padres e hijos, trabajadores y desempleados, clases altas y bajas o residentes en grandes ciudades y vecinos de un pequeño pueblo de perfil rural. Por otra parte, la relevancia socioestructural de estas variables es tan alta que no es aventurado señalarlas, con carácter general, como constantes en la configuración de los nodos y perfiles sociales. Por ello, parece razonable afirmar que todo análisis debe comenzar por (re)construir a partir de estos elementos la estructura social que queremos representar. Ahora bien, a estas variables señaladas por Ibáñez parece razonable añadir aquellas que se refieren a la ocupación, estado civil (y tipo de hogar/familia) y posicionamiento ideológico.

En cuanto a los rasgos categoriales, la eventualidad que define su naturaleza hace imposible listar si quiera algunos de ellos. Cualquier rasgo puede ser cate- 
gorial para un estudio determinado. Cabe señalar, sin embargo, algunos criterios que orienten la valoración de estos rasgos. A continuación se presentan algunos que pueden indicar un mayor poder diversificador y que a nuestro juicio pueden tener especial interés, aunque sin aspirar, en modo alguno, a la exhaustividad. Estos criterios se refieren a cuestiones factuales, conductuales y actitudinales, reproduciendo la clasificación presentada anteriormente:

- que el rasgo, característica o circunstancia que se expresa defina un «hecho» cuya presencia/ausencia introduzca diferencias relevantes. Por ejemplo, padecer una grave enfermedad crónica o sufrir un infarto.

- que el rasgo, característica o circunstancia que se expresa suponga, de alguna manera, la existencia de una relación jerárquica o de dominación, explícita o implícita. Por ejemplo, ser médico frente a ser enfermero/a o celador; y entre los médicos, ser Jefe de Servicio, Adjunto y Residente.

- que el rasgo, característica o circunstancia que se expresa establezca diferencias en hábitos o comportamientos relevantes para el estudio. Por ejemplo, recomendar habitualmente el uso de ciertos farmacos controvertidos en enfermos terminales.

- que el rasgo, característica o circunstancia que se expresa pueda interpretarse como la manifestación de un fuerte posicionamiento actitudinal positivo o negativo con relación al objeto de estudio o a otra circunstancia con incidencia en la investigación. Por ejemplo, manifestando un fuerte rechazo por la eutanasia.

\section{REFERENCIAS BIBLIOGRAFICAS}

AKKeR, D. A. y Day, G. S. (1989): Investigación de mercados. México, McGraw-Hill. ALONSo, L. E. (1998): La mirada cualitativa en sociología. Madrid, Editorial Fundamentos. AlviRA, F. (1983): "Perspectiva cualitativa/perspectiva cuantitativa en la metodología sociológica". Revista Española de Investigaciones Sociológicas, 22, pp. 53-57. ARRIBAS MACHO, J. M. (1998): «El modelo estadístico desde la perspectiva cualitativa». Revista EMPIRIA, 1. Madrid, UNED.

BERICAT, E. (1998): La integración de los métodos cuantitativo y cualitativo en la investigación social. Barcelona, Ariel Sociología.

Blalock, H. M. (1986): Estadística social, Méjico, FCE.

CAMARERo, L. A. y DEL VAL CID, C. (1999): Técnicas avanzadas de investigación social (técnicas cuantitativas). Madrid, UNED.

Clapham, C. (1992): Diccionario Oxford de matemática. Madrid, Celeste Ediciones.

CASTORIADIS, C. (1987): The Imaginary Institution of Society. Oxford, Polity Press.

- (1994): Los dominios del hombre: las encruccijadas del laberinto. Barcelona, Gedisa.

CASTRO Nogueira, M. A. (2001), La imagen de la investigación cualitativa en la investigación de mercados, Ponencia presentada en el Congreso español de Sociología, Salamanca.

Castro Noguera, M. A. y CAstro Nogueira, L. (2001, en prensa): «Hacia una correcta comprensión de la metodología cualitativa», Revista POLÍTICA y SOCIEDAD. 
Delgado, J. M. y Gutiérrez, J. (Coors) (1994): Métodos y técnicas cualitativas de investigación en Ciencias Sociales. Madrid, Editorial Síntesis.

GARCIA FERRANDO, M., IBAÑEZ, J. y Alvira, F. (1986): El análisis de la realidad social. Métodos y técnicas de investigación. Madrid, Alianza Universidad Textos.

GARCÍA FERRANDO, M. (1989): Socioestadística. Introducción a la estadística en Sociología. Madrid, Alianza.

GoRDON, W. y LANGMAI D. R. (1997): Qualitative market research. A practitioner's and buyer's guide. Aldershot, Gower Publishing.

Grande Esteban, I. y Abascal Fernandez, E. (1999): Fundamentos y técnicas de investigación comercial. Madrid, ESIC Editorial.

Greimas, A. J. (1987): Semántica estructural. Madrid, Gredos.

Hague, P. N. y Jackson, P. (1994): Cómo hacer investigación de mercados. Bilbao, Ediciones de la Universidad de Deusto.

IBAÑEZ, J. (1979): Más allá de la sociología. El grupo de discusión: técnica y crítica. Madrid, Siglo XXI.

- (1985): Del algoritmo al sujeto. Perspectivas de la investigación social. Madrid, Siglo XXI.

- (1994): El regreso del sujeto. La investigación social de segundo orden. Madrid, Siglo XXI.

KANT, I. (1790): Crítica del Juicio, parágrafo 46. Madrid, Austral, 1990, p. 263.

Ortega Martínez, E. (1990): Manual de investigación comercial. Madrid, Ediciones Pirámide.

ORTí, A. (1986): La apertura y el enfoque cualitativo o estructural.

«La entrevista abierta semidirectiva y la discusión de grupo», en garcía FerRANDO, M., Ibañez, J. y Alvira, F. (1986): El análisis de la realidad social. Métodos y técnicas de investigación, Madrid, Alianza Universidad Textos.

Reuter, U. (1995): The Seven Mortal Sins in the Qualitative Market Research. En Valentine, V. (infra).

Ruiz Olabuénaga, J. I. (1996): Metodología de la investigación cualitativa. Bilbao, Universidad de Deusto.

SARABIA SÁNCHEZ, F. J. (Coord.) (1999): Metodología para la investigación en marketing $y$ dirección de empresas. Madrid, Ediciones Pirámide.

SOlER Pujals, P. (1990): La Investigación motivacional en marketing y publicidad. Bilbao, Universidad de Deusto.

SOlER PuJAls, P. et al. (1997): La investigación cualitativa en marketing y publicidad. El grupo de discusión y el análisis de datos. Barcelona, Paidós. Papeles de Comunicación.

TAYLOR, S. J. y BOGDAN, R. (1994): Introducción a los métodos cualitativos de investigación. Barcelona, Paidós Básica.

VALENTINE, V. (1995): «Opening up the black box: switching the paradigm of qualitative research». En Looking trough the kaleidoscope: what is the qualitative mission? ESOMAR, Seminario celebrado en Paris, Diciembre de 1995.

VALles, M. S. (1997): Técnicas cualitativas de investigación social. Reflexión metodológica y práctica profesional. Madrid, Editorial Síntesis. 


\title{
RESUMEN
}

Estas páginas han surgido como respuesta a una necesidad de clarificación epistemológica, teórica y metodológica. Los autores de este artículo trabajan, desde el segundo semestre de 1999, en una investigación empírica cuyo objeto de análisis es la Unidad de Cuidados Intensivos de un gran Hospital del Servicio Público de Salud en Madrid. Esta UCI, como cualquier otra, es un espacio privilegiado en el que convergen aspectos funcionales, físicos, discursivos e imaginarios que hacen de ella un objeto de altísima densidad simbólica. Dicha investigación se aborda, en su fase de campo, desde una perspectiva cualitativa, cuyo diseño ha obligado a los autores a afrontar una revisión de los fundamentos de esta metodología. Estas páginas representan una parte de ese esfuerzo de (auto)clarificación. Concretamente, el artículo afronta un conjunto de temas centrales para la metodología cualitativa tales como la falta de unidad teórica y metodológica, los rasgos específicos de los objetos de investigación característicamente cualitativos y el problema de la representatividad de las conclusiones. En cierto modo, estas páginas presuponen las opiniones vertidas por los autores en su ensayo Hacia una correcta comprensión de la metodología cualitativa (en prensa, Revista POLÍTICA y SOCIEDAD) en el que se afrontaba una clarificación conceptual de esta perspectiva desde los planos ontológico-epistemológico y teórico.

\begin{abstract}
These pages are an attempt of clarifying a whole set of epistemological, theoretical and methodological problems. Since the second half of 1999, the authors are engaged into an empirical research focused in the Intensive Care Unit of one major Public Hospital of Madrid. This ICU, like many others, is a privileged space full of symbolic density rooted on its functional, physical and discursive features. The field work in progress takes on a qualitative approach whose design has driven the authors to face a rethinking of the very core of this methodology. In short, these notes -actually, field remarks- show something of that need of auto-clarifying. They deal with central subjects such as the lack of theoretical and methodological unity, the more relevant aspects of a true qualitative enquiry and the fundamental question about the so-called conclusions representativity. In some way, this article is a follow up of the essay Hacia una correcta comprensión de la metodología cualitativa (forthcoming: Revista POLíTICA y SOCIEDAD, 2001), where the authors confronted a rather more philosophical elucidation of this perspective from their ontological, epistemological and theoretical dimensions.
\end{abstract}

